\title{
SIMULTANEOUS ESTIMATION OF DRUGS PRESENT IN MICROBEADS FOR COLON-TARGETED DRUG DELIVERY SYSTEM
}

\author{
ABHISHEK KUMAR ${ }^{1 *}$, MEENAKSHI BHARKATIYA ${ }^{2}$ \\ ${ }^{1}$ Department of Pharmacy, Faculty of Pharmacy, Bhupal Nobles University, Udaipur, Rajasthan, India. ${ }^{2}$ Department of Pharmacy, \\ B.N. Institute of Pharmaceutical Sciences, B.N. University, Udaipur, Rajasthan, India. Email: abhishekkumargupta82@gmail.com
}

Received: 21 March 2019, Revised and Accepted: 26 September 2019

\section{ABSTRACT}

Objectives: The present study was aimed to develop Eudragit S100 coated colon-targeted sustained-release formulations of alginate-pectin and alginate-hydroxypropyl methylcellulose microbeads containing norfloxacin (NF) and tinidazole (TZ) for the treatment of amebiasis which was simultaneous estimated.

Methods: Taguchi L9 orthogonal array design has been used to optimize the composition and operating conditions for the preparation of formulations. Nine batches (P1-H5) were prepared by taking three independent variables $\left(\mathrm{X}_{1}\right.$ - drug:polymer ratio, $\mathrm{X}_{2}$ - concentration of sodium alginate, and $\mathrm{X}_{3}-$ curing time) at three levels (1, 2, and 3). Response variables studied for batches (P1-H5) were mean particle size ( $\mu$ m) (Y $)$, drug entrapment efficiency (\% w/w) $\left(\mathrm{Y}_{2}\right)$, and drug loading $(\% \mathrm{w} / \mathrm{w})\left(\mathrm{Y}_{3}\right)$. NF and TZ were simultaneous estimated by ultraviolet spectrophotometric method. Drug-polymer compatibility study was carried out by differential scanning calorimetry and Fourier-transform infrared spectroscopy and indicates no physicochemical interaction.

Results: Microbeads were analyzed for morphological characteristics, mean particle size, drug entrapment efficiency, drug loading, and in vitro drug release. The average size of optimized alginate-pectin microbeads was found to be $881 \pm 0.05 \mu \mathrm{m}$ with an entrapment efficiency of $78.50 \pm 0.28 \%$ (NF) and $86.50 \pm 0.32 \%$ (TZ) which was simultaneous estimated.

Conclusion: The studies concluded that formulated enteric-coated alginate-pectin microbeads after enteric coating can be used effectively for the delivery of NF and TZ to colon.

Keywords: Simultaneous estimation, Taguchi, Response variables, Independent variables, Drug entrapment efficiency, Drug loading, Curing time.

(C) 2019 The Authors. Published by Innovare Academic Sciences Pvt Ltd. This is an open access article under the CC BY license (http://creativecommons. org/licenses/by/4. 0/) DOI: http://dx.doi.org/10.22159/ajpcr.2019.v12i11.34236

\section{INTRODUCTION}

Targeted drug delivery into the colon is highly desirable for local treatment of a variety of bowel diseases such as ulcerative colitis, Crohn's disease, amebiasis, colon cancer, and systemic delivery of proteins and peptide drugs [1].

Optimization of process parameters by Taguchi design is an effort to minimize the variation in quality as well as to attain the quality near to the intended value simultaneously [2].

Tinidazole (TZ) is the drug of choice in most forms of amebiasis. TZ provided significantly higher cure rates in the treatment of symptomatic intestinal amebiasis.

Norfloxacin (NF) is effective orally and is rapidly bactericidal. It has relatively broad spectrum of action and is effective against Gram-positive and Gram-negative organisms.

$\mathrm{NF}$ and TZ combination therapy is available in conventional dosage form for the treatment of amebiasis. Conventional dosage forms (tablets and capsules) are inefficient for delivering drug to colon in appropriate concentration due to absorption or degradation in the hostile upper gastrointestinal tract (GIT).

To overcome these problems, colon-targeted multiparticulate drug delivery or microbeads can be formulated which have many advantages over single-unit preparations such as uniform dispersion and uniform absorption of drug in GIT.

The objective of the present study was to develop multiparticulate delivery system for site-specific delivery of NF and TZ using natural polysaccharide (pectin and hydroxypropyl methylcellulose [HPMC]) and $\mathrm{pH}$-sensitive polymer (Eudragit S100). This system was designed so as to protect the degradation of drug in the upper part of GIT using Eudragit S100 and to deliver TZ specifically to the colon, to reduce systemic dosing, and also to alleviate gastric distress $[3,4]$.

\section{MATERIALS AND METHODS}

Materials

$\mathrm{NF}$ and TZ were obtained as gift sample from Macleods Pharmaceuticals Limited, Mumbai, India. Sodium alginate was purchased from Titan Biotech Ltd., Bhiwadi (Rajasthan). Calcium chloride and HPMC were purchased from SD Fine-Chemicals Ltd., Mumbai, while pectin was procured from Thomas Baker Ltd., Mumbai. All other reagents and solvents used were of analytical grade.

Experimental design and analysis

Taguchi orthogonal array L9 design was used to optimize the composition and operating conditions for the preparation of microbeads. Factors selected for the study were drug:polymer ratio, concentration of sodium alginate, and curing time taken at low, medium, and high levels as shown in Table 1.

Response variables studied for prepared batches were mean particle size $(\mu \mathrm{m})(\mathrm{Y} 1)$, drug entrapment efficiency $(\% \mathrm{w} / \mathrm{w})(\mathrm{Y} 2)$, and drug loading $(\% \mathrm{w} / \mathrm{w})(\mathrm{Y} 3)$ as shown in Table 2. The experimental trials were performed in random order.

Nine batches of microbeads (P1-H5) were prepared as per experimental design layout of Taguchi L9 orthogonal array design. Calculations and statistical analysis of the results were carried out by multiple 
Table 1: Code for four variables at three different levels

\begin{tabular}{|c|c|c|c|c|}
\hline \multirow[t]{2}{*}{ S. No. } & \multirow[t]{2}{*}{ Variables } & \multicolumn{3}{|l|}{ Levels } \\
\hline & & Low (1) & Medium (2) & High (3) \\
\hline 1. & Drug: pectin & $1: 1$ & $1: 2$ & $1: 3$ \\
\hline 3. & Curing time & $30 \mathrm{~min}$ & $45 \min$ & $60 \min$ \\
\hline 4. & Drug: HPMC & $1: 1$ & $1: 2$ & $1: 3$ \\
\hline
\end{tabular}

HPMC: Hydroxypropyl methylcellulose

Table 2: Response variables

\begin{tabular}{lll}
\hline S. No. & Codes & Response variables \\
\hline 1. & $\mathrm{Y}_{1}$ & Mean particle size $(\mu \mathrm{m})$ \\
2. & $\mathrm{Y}_{2}$ & Drug entrapment efficiency $(\% \mathrm{w} / \mathrm{w})$ \\
3. & $\mathrm{Y}_{3}$ & Drug loading $(\% \mathrm{w} / \mathrm{w})$ \\
\hline
\end{tabular}

linear regression analysis (MLRA) to determine which factors have statistically significant effect on the response parameters.

\section{Simultaneous estimation of NF and TZ by ultraviolet (UV) spectrophotometric method \\ Preparation of standard stock solution}

Standard stock solutions $(100 \mu \mathrm{g} / \mathrm{mL})$ of $\mathrm{NF}$ and $\mathrm{TZ}$ were prepared by dissolving separately $10 \mathrm{mg}$ of drug each in $50 \mathrm{ml}$ methanol and volume is made up with water up to $100 \mathrm{ml}$. The working standard solutions of these drugs were obtained by dilution of the respective stock solution with water.

\section{Preparation of sample stock solutions}

An accurately weighed powder sample equivalent to $10 \mathrm{mg}$ of NF was transferred to a $100 \mathrm{ml}$ volumetric flask and dissolved in $50 \mathrm{ml}$ and sonicated for $15 \mathrm{~min}$ and volume made to $100 \mathrm{ml}$ with double distilled HPLC grade water. It was then filtered through Whatman filter paper No. 41. The solution was suitably diluted with double distilled HPLC grade water to obtain sample solutions containing $\mathrm{NF}$ and $\mathrm{TZ}$ in the concentrations ratio of $2: 3 \mu \mathrm{g} / \mathrm{mL}$, respectively, as in the formulation. The final concentrations are $10 \mu \mathrm{g} / \mathrm{mL}$ of NF and $15 \mu \mathrm{g} / \mathrm{mL}$ of TZ.

\section{Simultaneous equation method}

In this method, $273 \mathrm{~nm}$ and $310 \mathrm{~nm}$ were selected as the two sampling wavelengths. NF and TZ exhibited linearity with absorbances in the range of $1-20 \mu \mathrm{g} / \mathrm{mL}$ and $1-40 \mu \mathrm{g} / \mathrm{mL}$ at their respective selected wavelengths. For simultaneous estimation of NF and TZ, mixed standards containing NF and $\mathrm{TZ}$ in a concentration ratio of $2: 3 \mu \mathrm{g} / \mathrm{mL}$ each were prepared by appropriate dilution of the standard stock solutions with distilled HPLC grade water

The absorbances of the mixed standard solutions were measured at the selected wavelengths. A set of two simultaneous equations was used for obtaining the concentration of $\mathrm{NF}$ and $\mathrm{TZ}$ as follows:

$$
\begin{gathered}
C_{x}=\frac{A_{2} \mathrm{ay}_{1}-A_{1} a_{2}}{a_{2} \mathrm{ay}_{1}-\mathrm{ax}_{1} \mathrm{ay}_{2}} \\
\mathrm{C}_{\mathrm{y}}=\frac{\mathrm{A}_{2} \mathrm{ax}_{1}-\mathrm{A}_{1} \mathrm{ax}_{2}}{\mathrm{ax}_{2} \mathrm{ay}_{1}-\mathrm{ax}_{1} \mathrm{ay}_{2}}
\end{gathered}
$$

Where, $A_{1}$ and $A_{2}$ are absorbances of mixture at $273.0 \mathrm{~nm}$ and $310.0 \mathrm{~nm}$, respectively, $\mathrm{ax}_{1}$ and $\mathrm{ax}_{2}$ are absorptivities of NF at $\lambda_{1}$ and $\lambda_{2}$, respectively, and $\mathrm{ay}_{1}$ and $\mathrm{ay}_{2}$ are absorptivities of $\mathrm{TZ}$ at $\lambda_{1}$ and $\lambda_{2}$, respectively. $\mathrm{C}_{\mathrm{x}}$ and $\mathrm{C}_{\mathrm{y}}$ are concentrations of $\mathrm{NF}$ and $\mathrm{TZ}$, respectively. The concentration of $\mathrm{NF}$ and $\mathrm{TZ}$ in mixed standard and tablets formulation can be obtained by solving equation (2.3.3.1) and (2.3.3.2) [5].

\section{Formulation development}

Introduction to the preparation of microbeads

Microbeads were prepared using ionotropic gelation technique. Two different sets of microbeads were prepared using alginate-pectin and
alginate-HPMC in combination. Various formulation parameters such as the concentration of sodium alginate, pectin, and HPMC were optimized on the basis of average size, shape, entrapment efficiency, and in vitro drug release (Table 3 ).

\section{Loading efficiency (\%)}

Accurately weighed $100 \mathrm{mg}$ of microbeads was extracted in $100 \mathrm{ml}$ phosphate buffer, pH 7.4 for $24 \mathrm{~h}$. Extracted solution was filtered and a sample of $5 \mathrm{ml}$ was withdrawn from this solution. Sample was diluted to $50 \mathrm{ml}$ with distilled water and assayed spectrophotometric ally (Systronics AU2701) at $273 \mathrm{~nm}$ and $310 \mathrm{~nm}$ to determine the content of drug in microbeads. All the determinations were performed in triplicate. Drug loading (\%) of the microbeads was calculated using the equation:

Drug loading (\%)=Drug content $\times 100$ weight of drug+polymer

\section{Statistical analysis}

Response variables were analyzed using Microsoft Excel spreadsheet, 2007. MLRA was used to develop equations for mean particle size $\left(\mathrm{Y}_{1}\right)$, percentage drug entrapment efficiency $\left(\mathrm{Y}_{2}\right)$, and percentage drug loading $\left(\mathrm{Y}_{3}\right)$.

$$
Y=\beta_{0}+\beta_{1} X_{1}+\beta_{2} X_{2}+\beta_{3} X_{3}
$$

Where, $\mathrm{Y}$ is estimated response of response variable, $\beta_{0}$ is arithmetic mean response of nine batches, $\beta_{1}$ is estimated coefficient for factor $\mathrm{X}_{1}$, $\beta_{2}$ is estimated coefficient for factor $X_{2}$, and $\beta_{3}$ is estimated coefficient for factor $\mathrm{X}_{3}$

\section{Differential scanning calorimetry (DSC)}

DSC measurements were done on DSC Q10V 9.0 build 275 model water limited instrument by heating the samples from $25^{\circ} \mathrm{C}$ to $250^{\circ} \mathrm{C}$ at the rate of $20^{\circ} \mathrm{C} / \mathrm{min}$ in a nitrogen atmosphere (flow rate, $10 \mathrm{~mL} / \mathrm{min}$ ).

\section{Fourier-transform infrared (FTIR) spectroscopy}

FTIR spectra were taken on FTIR - Shimadzu instrument to investigate the possible chemical interactions between drug and polymer. $1 \mathrm{mg}$ of sample was triturated with $300 \mathrm{mg}$ of $\mathrm{KBr}$ in a mortar. A little amount of triturated sample was compressed at $10 \mathrm{~kg} / \mathrm{cm}^{2}$ into a pellet maker. Pellet was kept on sample holder and scanned from $4000 \mathrm{~cm}-1$ to $400 \mathrm{~cm}-1$.

\section{In vitro drug release study from core microbeads}

The in vitro drug release study of core alginate-pectin microbeads and alginate-HPMC microbeads was carried out using USP Dissolution Apparatus II (Veego DA, 6DR Japan) at $37 \pm 0.5^{\circ} \mathrm{C}$ at $100 \mathrm{rpm}$ using $900 \mathrm{ml}$ of simulated intestinal fluid of $\mathrm{pH} 6.8$ as dissolution medium for $8 \mathrm{~h}$. A muslin cloth was tied over the basket to prevent the slippage of beads from the basket. A fixed volume of $5 \mathrm{ml}$ sample solution was withdrawn at predetermined intervals, which was then filtered through Whatman filter paper, diluted suitably, and analyzed spectrophotometrically using UV-visible spectrophotometer (UV-1700 Pharmaspec, Shimadzu) at $273 \mathrm{~nm}$ for NF and $310 \mathrm{~nm}$ for TZ. Equal volume of fresh dissolution medium was added immediately after withdrawal of the test sample, the percentage drug release was calculated from the simultaneous equation (2.3.3.1 and 2.3.3.2) [6] 
Table 3: Composition of microbeads

\begin{tabular}{|c|c|c|c|c|c|c|}
\hline Formulation code & Sodium alginate $(\%)$ & Pectin (\%) & HРMC (\%) & Calcium chloride $(\%)$ & Cross-linking agent (ml) & Curing time (min) \\
\hline $\mathrm{P} 1$ & 1.00 & 0.50 & - & 2 & 1 & 45 \\
\hline $\mathrm{P} 2$ & 1.00 & 1.00 & - & 2 & 1 & 45 \\
\hline P3 & 1.00 & 1.50 & - & 2 & 1 & 45 \\
\hline H1 & 1.00 & - & 0.75 & 2 & 1 & 45 \\
\hline $\mathrm{H} 2$ & 1.00 & - & 0.25 & 2 & 1 & 45 \\
\hline H3 & 1.00 & - & 0.50 & 2 & 1 & 45 \\
\hline $\mathrm{P} 4$ & 2.00 & 0.50 & - & 2 & 1 & 45 \\
\hline P6 & 2.00 & 1.50 & - & 2 & 1 & 45 \\
\hline $\mathrm{H} 4$ & 2.00 & - & 0.25 & 2 & 1 & 45 \\
\hline H5 & 2.00 & - & 0.50 & 2 & 1 & 45 \\
\hline H6 & 2.00 & - & 0.75 & 2 & 1 & 45 \\
\hline P7 & 3.00 & 0.50 & - & 2 & 1 & 45 \\
\hline P8 & 3.00 & 1.00 & - & 2 & 1 & 45 \\
\hline P9 & 3.00 & 1.50 & - & 2 & 1 & 45 \\
\hline H7 & 3.00 & - & 0.25 & 2 & 1 & 45 \\
\hline H9 & 3.00 & - & 0.75 & 2 & 1 & 45 \\
\hline
\end{tabular}

HPMC: Hydroxypropyl methylcellulose

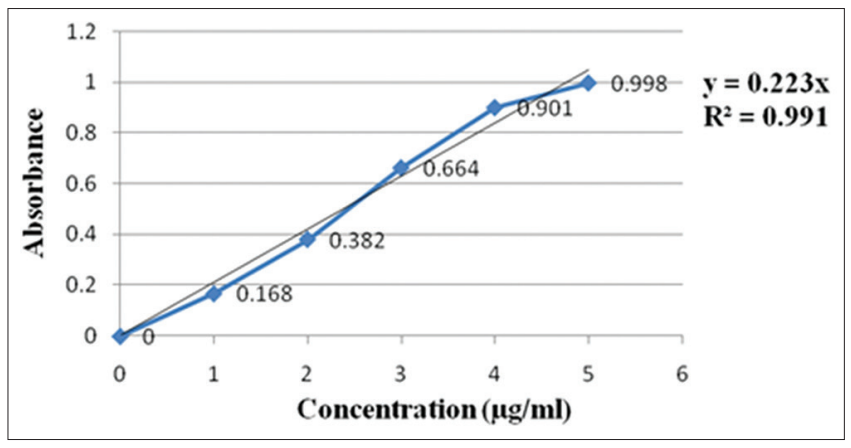

Fig. 1: Regressed curve of norfloxacin in methanol at $273 \mathrm{~nm}$

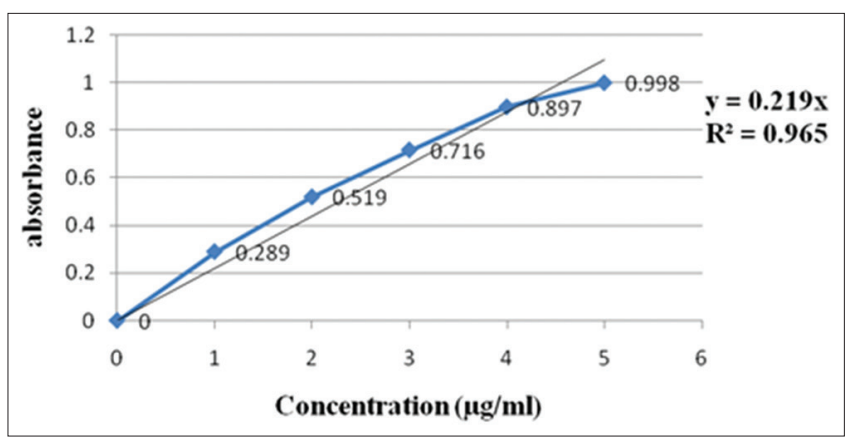

Fig. 2: Regressed curve of tinidazole in methanol at $310 \mathrm{~nm}$

In vitro drug release study from coated microbeads

The drug release study of coated alginate-pectin microbeads was carried out using USP Dissolution Apparatus II (Veego DA, 6DR Japan) at $37 \pm 0.5^{\circ} \mathrm{C}$ at $100 \mathrm{rpm}$ using $900 \mathrm{ml}$ of simulated gastric fluid of $\mathrm{pH} 1.2$ as dissolution medium for initial $2 \mathrm{~h}$, followed by phosphate buffer (pH 7.4) for next $3 \mathrm{~h}$. The beads were then transferred in PBS $\mathrm{pH} 6.8$ and the release was noted up to $8 \mathrm{~h}$. A fixed volume $(5 \mathrm{ml})$ of sample solution was withdrawn and analyzed spectrophotometrically for quantitative estimation of drugs released as described in earlier section $2.4 .7[7,8]$.

\section{RESULTS AND DISCUSSION}

\section{Preparation of standard curve of NF and TZ}

Identification of drug was carried out using UV spectroscopy. The calibration curve of NF and TZ was prepared in methanol. The data were regressed to obtain straight line. The regression coefficient of NF and TZ was found to be 0.991 and 0.965 , respectively, indicating a good linearity, Figs. 1 and 2. The calibration curve obeyed Beer's Lambert law in the concentration range of $0-6 \mu \mathrm{g} / \mathrm{ml}$.

Simultaneous estimation of NF and TZ by UV spectrophotometric methods

An accurately weighed microbeads sample equivalent to $10 \mathrm{mg}$ of $\mathrm{NF}$ was transferred to a $100 \mathrm{ml}$ volumetric flask and dissolved in $50 \mathrm{ml}$ and sonicated for $15 \mathrm{~min}$ and volume made to $100 \mathrm{ml}$ with double distilled HPLC grade water. It was then filtered through Whatman filter paper No. 41. The solution was suitably diluted with double distilled HPLC grade water to obtain sample solutions containing $\mathrm{NF}$ and $\mathrm{TZ}$ in the concentrations ratio of $2: 3 \mu \mathrm{g} / \mathrm{mL}$, respectively, as in the formulation. The final concentrations are $10 \mu \mathrm{g} / \mathrm{mL}$ of $\mathrm{NF}$ and $15 \mu \mathrm{g} / \mathrm{mL}$ of TZ.

Absorbance value of Norfloxacin and Tinidazole is given in Tables 4 and 5 .

Observation of Norfloxacin and Tinidazole in Simultaneous estimation is given in Tables 6-8.

The concentration of NF and TZ was found to be $9.67 \mu \mathrm{g} / \mathrm{ml}$ and $14.40 \mu \mathrm{g} / \mathrm{ml}$ which were very close to the actual concentration of drugs present in microbeads formulation.

\section{Drug excipient interaction}

Drug excipient interaction was carried out by DSC. In this, DSC thermogram of NF, TZ, sodium alginate, and pectin polymer recorded using a DSC.

The thermogram of mixture of drugs (NF and TZ) and excipients shown that there was no interaction between drugs and polymer used in Fig. 3.

\section{SUMMARY AND CONCLUSION}

The aim of the present study was to develop Eudragit S100 coated colontargeted sustained-release formulations of alginate-pectin microbeads and alginate-HPMC microbeads containing NF and TZ for the treatment of amebiasis which was simultaneous estimated.

The design of the colon-targeted microbeads combines two approaches: $\mathrm{pH}$-sensitive delivery and biodegradation in the colonic environment. For microbeads preparation, drug was first entrapped within the alginate-pectinate beads using ionotropic gelation technique and then these microbeads were coated within Eudragit S-100 polymer by solvent evaporation method. Polymer was selected to target the colon as it starts dissolving at $\mathrm{pH} 1.2$ in the stomach, 


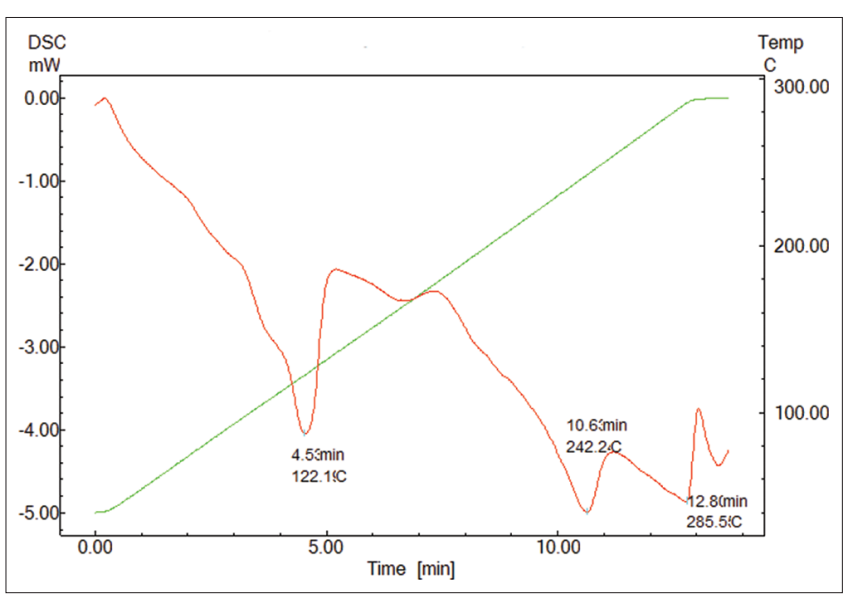

Fig. 3: Differential scanning colorimetric report of sodium alginate, pectin, norfloxacin, and tinidazole mixture

Table 4: Absorbance value of Norfloxacin

\begin{tabular}{ll}
\hline Concentration $(\mu \mathbf{g} / \mathbf{m l})$ & Absorbance $(\mathbf{n m})$ \\
\hline 0 & 0 \\
1 & $0.168 \pm 0.06$ \\
2 & $0.382 \pm 0.05$ \\
3 & $0.664 \pm 0.07$ \\
4 & $0.901 \pm 0.06$ \\
5 & $0.998 \pm 0.06$ \\
\hline
\end{tabular}

Table 5: Absorbance value of Tinidazole

\begin{tabular}{ll}
\hline Concentration $(\mu \mathrm{g} / \mathrm{ml})$ & Absorbance $(\mathbf{n m})$ \\
\hline 0 & 0 \\
1 & $0.289 \pm 0.03$ \\
2 & $0.519 \pm 0.04$ \\
3 & $0.716 \pm 0.03$ \\
4 & $0.897 \pm 0.05$ \\
5 & $0.998 \pm 0.05$ \\
\hline
\end{tabular}

Table 6: NF in simultaneous estimation

\begin{tabular}{ll}
\hline \multicolumn{2}{c}{$\mathbf{N F}$} \\
\hline $\mathrm{ax}_{1} 273 \mathrm{~nm}$ & $0.0913 \pm 0.03$ \\
$\mathrm{ax}_{2} 11 \mathrm{~nm}$ & $0.0254 \pm 0.05$ \\
\hline NF: Norfloxacin
\end{tabular}

Table 7: TZ in simultaneous estimation

\begin{tabular}{ll}
\hline \multicolumn{2}{c}{ TZ } \\
\hline ay $_{1} 273 \mathrm{~nm}$ & $0.017 \pm 0.07$ \\
ay $_{2} 311 \mathrm{~nm}$ & $0.060 \pm 0.03$ \\
\hline TZ: Tinidazole
\end{tabular}

Table 8: NF and TZ in simultaneous estimation

\begin{tabular}{ll}
\hline \multicolumn{3}{c}{$\mathbf{N F}+\mathbf{T Z}(2: 3 \mu \mathrm{g} / \mathrm{ml})$} \\
\hline$\left(\mathrm{A}_{1} 273 \mathrm{~nm}\right)$ & $1.188 \pm 0.02$ \\
$\left(\mathrm{~A}_{2} 311 \mathrm{~nm}\right)$ & $1.100 \pm 0.03$ \\
\hline
\end{tabular}

NF: Norfloxacin, TZ: Tinidazole

but the microbeads coated with Eudragit E-100 prevented the drug release and prolonging its release while transit through the intestine, thereby, maintaining its effective plasma concentration over longer duration. Eudragit E-100 is insoluble in acidic medium but dissolves above $\mathrm{pH} 7.0$ [9].
The calculated regression coefficients for zero-order, first-order, and Higuchi models were $0.777,0.906$, and 0.951 . The in vitro drug release of alginate-pectin microbeads was best explained by Higuchi models as the plot showed the highest linearity, followed by the first order. The Korsmeyer-Peppas release exponent $\mathrm{n}$ for the optimized formulation (P5) was 1.416 indicating that the release was governed by Non-Fickian Super Case II Transport.

Microbeads stored at $40 \pm 0.5^{\circ} \mathrm{C}$ showed $\mathrm{K}$ value as $3.42 \times 10^{-4}$ and $\mathrm{t}_{10}$ value as 304 days, while those stored at room temperature $\left(25 \pm 0.5^{\circ} \mathrm{C}\right)$ showed $\mathrm{K}$ value as $2.66 \times 10^{-4}$ and $\mathrm{t}_{10 \%}$ value as 390 days. This indicates that microbead formulations are stable.

The concentration of NF and $\mathrm{TZ}$ was found to be $9.67 \mu \mathrm{g} / \mathrm{ml}$ and $14.40 \mu \mathrm{g} / \mathrm{ml}$ which were very close to the actual concentration of drugs present in microbeads formulation.

\section{CONCLUSION}

Microbeads were developed using Taguchi L9 orthogonal array design and drugs were simultaneous estimated. The concentration of NF and TZ was found to be very close to the actual concentration of drugs present in microbeads formulation. Hence, the studies concluded that formulated enteric-coated alginate-pectin microbeads after enteric coating can be used effectively for the delivery of NF and TZ to colon.

\section{ACKNOWLEDGMENTS}

The author would like to express heartily thanks to Macleods Pharmaceutical Limited, Mumbai, for providing NF and TZ as a free gift samples and also thanks to B.N. Institute of Pharmaceutical Sciences, B.N. University, for providing the research facility.

\section{AUTHORS' CONTRIBUTIONS}

Dr. Meenakshi Bharkatiya constructed an idea for manuscript and planned methodology to reach the conclusion. Mr. Abhishek Kumar was taken responsibility in execution of the experiments, data management, reporting, logical interpretation, and presentation of the results. Mr. Abhishek Kumar organized the manuscript and Dr. Meenakshi Bharkatiya supervised the manuscript preparation and reviewed the manuscript.

\section{CONFLICTS OF INTEREST}

The author confirms that there are no conflicts of interest, financial or otherwise.

\section{REFERENCES}

1. Kala D, Sudhakaran CR. In vivo evaluation of budesonide microspheres for colon specific drug delivery. Int J Pharm Pharm Sci 2016;8:159-65.

2. Jose S, Fangueiro JF, Smitha J, Cinu TA, Chacko AJ, Premaletha K, et al. Cross-linked chitosan microspheres for oral delivery of insulin: Taguchi design and in vivo testing. Colloids Surf B Biointerfaces 2012;92:175-9.

3. Purushothaman M, Vijaya RJ, Prabakaran L. Colon targeted drug delivery system - An overview. Pharm Rev J 2010;8:1-23.

4. Chourasia MK, Jain SK. Pharmaceutical approaches to colon targeted drug delivery systems. J Pharm Sci 2003;6:33-66.

5. Pant M, Dadare K, Khatri NC. Application of UV spectrophotometric methods for simultaneous estimation of norfloxacin and tinidazole in bulk and tablet dosage forms. Pharma Chem 2012;4:1041-6.

6. Patel HK, Nagle A, Murthy RS. Characterization of calcium alginate beads of 5-fluorouracil for colon delivery. Asian J Pharm 2018;12:241-5.

7. Bagyalakshmi J, Arun RR, Ravi TK. Fomulation, physical charecterisation and in-vitro release studies of prednisolone alginate beads for colon targeting by ionotropic gelation. Int J Compr Pharm 2011;2:1-4.

8. Khan MS, Sridhar BK. Development and evaluation of pH-dependent micro beads for colon targeting. Indian J Pharm Sci 2010;72:18-23.

9. Chopra R, Kaur KP, Bedi N. Colon specific delivery of eudragit E-100 and eudragit-FS30D coated tablets of leflunomide using chitosan-chondroitin sulphate interpolymer complex. Int J Pharm Pharm Sci 2015;7:286-91. 